\title{
Renunciando às garantias da Verdade: Agamben e a arte*
}

\author{
AGAMBEN, Giorgio. O homem sem conteúdo. \\ Tradução, notas e posfácio de Claudio Oliveira. Belo \\ Horizonte: Autêntica Editora, 2012 (Coleção \\ Filô/Agamben; 2).
}

\section{Guilherme F. Waterloo Radomsky ${ }^{* *}$}

$O$ homem sem conteúdo é o primeiro livro de Giorgio Agamben e foi publicado na Itália no ano de 1970 . Por razões diversas, inclusive pelo custo oneroso da circulação e da tradução de livros estrangeiros, esta obra chega tardiamente ao leitor não familiarizado com a língua italiana (a edição em inglês foi publicada somente em 1999). O homem sem conteúdo mostra com vigor um conjunto de ideias e problemas que viriam a estar presentes em seus mais conhecidos livros por parte do público brasileiro, a série que constitui a coleção Homo Sacer. Embora O homem sem conteúdo seja uma obra sobre arte e sociedade, expõe teses que são reveladoras e surpreendentes sobre a arquitetura do pensamento ocidental.

Num estilo muito próprio, Agamben tem como fio condutor inicial um problema: e se a observação kantiana, que coloca no epicentro da estética o espectador desinteressado - que julga o belo, mas não o cria -, jamais tivesse o poder de influência para a formação do regime de verdade da arte ocidental moderna? Este ponto de partida diz respeito à crítica de Nietzsche dirigida a Kant que, na Genealogia da moral, potencializa o artista interessado e criativo o qual seria o núcleo experiencial que a estética perdeu. Em um dos seus "giros" filosóficos, Kant teria recolocado o problema estético para o apreciador, aquele que julga (portanto conhece) desinteressadamente a arte, e isto definiu a reflexão e a concepção sobre arte nos últimos séculos. Mais adiante no livro, outra pergunta-enigma nos arremessa a uma reflexão que encaminha a crítica a ser realizada nas páginas seguintes: o que aconteceu na convergência entre o niilismo e a

\footnotetext{
* Resenha recebida em 13/12/2012 e aprovada para publicação em 28/01/2013.

** Professor do Programa de Pós-graduação em Sociologia, do Departamento de Sociologia do curso de Ciências Sociais e do Programa de Pós-graduação em Desenvolvimento Rural, Universidade Federal do Rio Grande do Sul. E-mail: guilherme.radomsky@ufrgs.br.
} 
arte do século $\mathrm{XX}$, especialmente a produção pós-Duchamp, e quais suas consequências políticas e filosóficas?

Passando por períodos históricos singulares, tal como a Grécia Antiga e a noção de que a arte nunca foi desinteressada em Platão (por isso mesmo ela temia sua capacidade transformadora), o autor nos direciona a uma figura emblemática de nosso tempo: o surgimento do homem de gosto na Europa do século XVII. Num exercício genealógico fascinante, Agamben nos diz que até este momento não havia distinção entre o bom e o mau gosto. "A sensibilidade daquele tempo não fazia grande diferença entre as obras de arte sacra e os bonecos mecânicos [...]" (p. 38). Ademais, desinteresse não era atributo que fizesse parte desta economia simbólica. Príncipes e pontífices não eram alheios ao trabalho artístico, a ponto de deixar de lado questões de governo para se dedicar à arte. Então, começa a ficar clara a consequência de uma estética do espectador que passou a adquirir relevância: "A nossa moderna educação estética nos acostumou a considerar normal [...] reprovar qualquer intrusão no trabalho do artista" (p. 40). Paulatinamente, cresce a importância do homem de gosto que julga e frui a obra paralelamente ao aspecto de excentricidade, eventual desequilíbrio e necessária liberdade do artista. No polo do examinador da arte, "[T]udo se passa, em suma, como se o bom gosto, permitindo, a quem tem o seu dom, perceber o point de perfection da obra de arte, terminasse, na realidade, por torná-lo indiferente a ela" (p. 45). É como se dois mundos conectados, mas desiguais, estivessem sendo formados por relações necessárias entre eles e que nos leva ao fim de um tipo de experiência com a arte. A nova experiência estaria proporcionando um tipo de ser humano culto, refinado e desinteressado, que, no limite, vê na arte sua essência se, e apenas se, um processo de indiferença estiver fundamentando os valores desta estética.

A arte pela arte se naturaliza e, quem sabe, seja a modalidade geradora de um paradoxo que nos acompanha desde então - a indiferença permite um campo artístico com especialistas de elevado grau de saber e, assim, a arte se permite viver num casulo como se não fosse relacional aos processos sociais. De outro, o artista em sua excentricidade e liberdade, um gênio solitário, por vezes incompreendido, cuja intromissão de outros em sua criação não é nada senão violência. Em ambos, o risco é o da nadificação da experiência, ou a experiência do Nada. É aqui que Agamben indaga, seguindo Heidegger, se o espírito niilista encontra convergências com o destino da arte - pergunta que retornará no fim do livro.

O filósofo se detém no debate sobre o que é a poesia. Novamente com o modo peculiar de trabalhar com a etimologia, Agamben observa a relação entre poiesis e o fazer humano que pertence ao mundo da téchne. Soa como 
se o "reino da arte" perdesse sua potencialidade justamente por demarcar sua particularidade, pois a arte e o fazer humano criativo são o mesmo e sugerem justamente o que seja o humano em relação aos outros animais. Mas, é claro, o autor nos recorda que, embora técnica seja uma palavra antiga, o seu estatuto após a Revolução Industrial se consolida de maneira oposta ao estatuto da estética, ambas entendidas como sendo desdobradas em planos separados. Qual a diferença? Ecoando um célebre texto de Walter Benjamin, a reprodutibilidade está para a técnica assim como a originalidade está para a obra de arte. Com fronteiras tênues e sempre em terreno movente, técnica e arte não parecem dar as mãos, mas nunca estão distantes como poder-se-ia pensar, tal são os investimentos em valores de autenticidade como narrativa crucial de nosso tempo para todos os produtos e processos. O inverso também é verdade, se quisermos. Então, surpreendentemente, em nossa época "a exigência de uma autenticidade da produção técnica e aquela de uma reprodutibilidade da criação artística fizeram nascer duas formas híbridas, o ready-made e a pop-art [...]" (p. 108). A simetria mais curiosa da inversão nadificadora da arte estaria na tal reciprocal ready-made "em que pensava Duchamp quando sugeria usar um Rembrandt como mesa de passar roupa" (p. 89). O processo de autonadificação da arte teria levado não à morte, mas a sua perpetuação indefinida e irônica.

Ocorre que em filosofia e ciências sociais não raramente encontramos sobreposições parciais entre poiesis, praxis, produção, criação, invenção. Recorrendo a Marx de maneira astuta, Agamben sustenta que prâxis e poíesis (grafadas desta forma na tradução) são processos diferentes, ambas apontando para o sentido de fazer, mas o primeiro sendo um mero fazer, denotando ação humana, e o segundo, produzir (ou, como grafa o autor, pro-duzir) sublinhando "o fato de que, nela, algo viesse do não ser ao ser, da ocultação à plena luz da obra" (p. 118). Antecipando argumentos desenvolvidos especialmente no primeiro volume de Homo Sacer, e aqui versando sobre o mundo antigo, afirma que "[...] enquanto a poíesis constrói o espaço em que o homem encontra a sua própria certeza e assegura a liberdade e a duração da sua ação, o pressuposto do trabalho é, ao contrário, a nua existência biológica [...]" (p. 119). Ao longo dos séculos, - Ocidente apaga as especificidades de prâxis e poíesis e assim a noção de poíesis se desloca para o caráter operário do artista, ainda que gênio criador. Paralelamente, enquanto o trabalho era vil no mundo antigo, a filosofia política liberal trata de torná-lo a essência da produção de valor e centro da atividade humana. 
Contudo, se o autor da Ideologia alemã permanece no redemoinho da práxis como atividade humanizadora, intensificando-a como atividade universal genérica, será Nietzsche quem virá a estilhaçar este problema que se aprofundou nos planos conceituais quando se percorre o caminho de Locke a Marx. Para Agamben, o problema da arte não aparece no pensamento do autor de Zaratustra, pois tudo o que constitui como questão filosófica é pensamento de arte. Mais ainda: "arte é o nome que ele dá ao traço essencial da vontade de potência" (p. 149). Talvez Nietzsche tenha sido aquele que colapsou a arte como essência ou verdade, pois ela, além de ter mais valor que a verdade, é o pilar que temos - como humanos - para não afundarmos frente à verdade, reflete Agamben. Portanto, estaria na realização total da arte na vida, a epifania no seu extremo, sua afronta ao niilismo?

Em determinadas passagens do livro, ser humano e pro-duzir arte entram em certa indecidibilidade. "O dom da arte é, portanto, o dom mais original, porque é o dom do próprio sítio original do homem" (p. 164). A obra de arte não seria nem um "valor" cultural nem um objeto privilegiado a ser fruído pelo espectador; ela está em uma dimensão mais essencial, "porque permite ao homem, a cada vez, ter acesso à sua estatura original na história e no tempo" (p. 164).

Para além da genealogia crítica que concede ao pensamento kantiano o poder da reviravolta em que o homem de conteúdo dominará o exercício de julgamento do belo e de afirmação ontológica sobre o que seja a estética, a preocupação de Agamben é também indagar o que ocorreu entre a emergência da modernidade e o colapso da experiência tradicional. Nada melhor que a própria arte para se perceber o ponto de mutação de uma época. O que ela permitiria num mundo de transformações e nas quais o destino da obra artística se confronta com seu "fim", sua perpetuação como ironia e sua falta de definição? Caso tudo possa assumir estatuto artístico, poder-se-ia indagar se nada pode ser arte. Recuperando mais uma vez os escritos de Benjamin, agora a leitura sobre a aura e a modernidade em Baudelaire, Agamben responde que a arte perde sua autoridade e a garantia que derivavam de seu pertencimento às tradições, para as quais ela servia de ponte entre passado e presente. Entretanto, sem abandonar a sua autenticidade, ela se torna "o espaço em que se cumpre o mais inefável dos mistérios: a epifania da beleza estética" (p. 172). Irrompe a sensação de que o argumento a ser destruído retorna com toda a força agora. Parcialmente, mas observamos que a arte passa então a ser o elo unificador da experiência, ao mesmo tempo que se atualiza como o signo da impossibilidade desta mesma experiência. 
Reinventar uma nova autoridade para a arte é refletir sobre sua tarefa de apontar para a intransmissibilidade da cultura como um novo valor, pois é o choque a característica da modernidade; a arte quer sobreviver à ruína da tradição e ela própria se coloca neste interstício da impossibilidade de transmitir. Signo do estilhaço, lampejo de conexão, ponto nevrálgico do que é ser humano, ícone da perda da transmissão da tradição, para Agamben a arte é o "último liame que ainda une o homem ao seu passado" (p. 173). O livro termina ao nos dizer que "[T]ransformando em procedimento poético o princípio do atraso do homem frente à verdade e renunciando às garantias do verdadeiro por amor à transmissibilidade, a arte consegue, assim [...] fazer da incapacidade do homem de sair do seu estado histórico permanentemente suspenso no intermundo entre velho e novo, passado e futuro, o espaço mesmo no qual ele pode ganhar a medida original da própria demora no presente e reencontrar a cada vez o sentido da sua ação" (p. 184).

A arte, neste ponto de vista, parece assumir um rol semelhante ao anjo da história (Angelus Novus), personagem conceitual inspirado em Klee que surge na tese número nove de Walter Benjamin ("Sobre o conceito de história"). Teria ela força para acordar os mortos e juntar os fragmentos, reerguer a teia rompida entre presente e passado? Como sabemos, do paraíso sopra uma tempestade que impele $o$ anjo da história num movimento irresistível para o futuro e ele somente testemunha o amontoar de ruínas do passado. Como tarefa que pode ser própria da arte, entretanto, é possível que ela não se canse de nos expor simultaneamente à perda e à tentativa de transmissibilidade da experiência. 